\title{
SATISFACTION AND CHARACTERISTICS OF AIRBNB DEMAND IN BUDAPEST
}

\author{
Klára Morvay Karakas ${ }^{1}$ \\ Received: January 22, 2017 | Accepted: July 18, 2017
}

\begin{abstract}
The past two years Budapest has been placed on the list of the most visited European cities. in 2015 The total number of tourists arriving to Budapest increased by $7.6 \%$, the number of guest nights showed quite a big (6.8\%) growth as well, while the income of the commercial accommodation types increased by 15.5\% (Hungarian Central Statistical Office, 2016). After the bankruptcy of Malév (Hungarian Airlines) in 2012 very different type of guests appeared in Budapest. The rise of sharing economy may explain this considerable growth and change.
\end{abstract}

The goal of this article is to get an insight to the Airbnb market in Budapest. The huge growth on supply side will be proved by data. Understanding of Airbnb demand is based on primary research. Demographic features and spending structure is presented, as well as the guest satisfaction with Airbnb and Budapest - as a touristic product.

Keywords: sharing economy, Airbnb, guest characteristics, satisfaction, Budapest

\section{INTRODUCTION}

Sharing economy is a new phenomenon in the world economy. Trust, convenience and a sense of community are all factors in pushing adoption of the new model forward. Sharing economy in Europe can increase to 570 billion Euros in 2016, which is twenty times bigger than the previous year's number, in 2015. Based on a research of Price Waterhouse Coopers (2015), its most important sectors are the followings: community finance, community-based accommodation sharing, passenger transport, on-demand household and professional services.

From the above listed sectors, the community-based accommodation sharing is going to be the focal point of this research. New software platforms use modern information technology, including full-featured web sites and mobile apps, to allow service providers and consumers to transact with relative ease and increased trust. These platforms provide notable benefits including reducing transaction costs, improving allocation of

\footnotetext{
Department of Catering, Tourism and Catering Management, Budapest Business School, contact: karakasnemorvay.klara@uni-bge.hu
} 
resources, and information and pricing efficiencies (Edelman and Geradin, 2015). The sharing economy is thriving in the travel industry today, with apartment dwellers or home owners using a variety of distribution channels to rent out their unused units or spare bedrooms to travellers seeking alternatives to traditional hotel stays (HotelNewsNow, 2015, Guttentag, 2015)

\title{
LITERATURE REVIEW
}

\begin{abstract}
Airbnb
Couchsurfing, Homestay, Love Home Swap, Home Exchange, Bedycasa, Culture GoGo, Homestayin, World Wide Opportunities on Organic Farms (Wwoof) and Airbnb are already existing communities and/or websites with almost the same purpose: travelling while meeting people from different cultures, ages and genders, avoiding high hotel rates (Lieber, 2012).

One of the most popular one of them is Airbnb, founded in 2008 by three entrepreneurs: Joe Gebbia, Brian Chesky and Nathan Blecharczyk. Airbnb’s founders recognized the traveling public want an alternative to traditional hotels and have developed a seamless platform to operate and sell that inventory (Oskam and Boswijk, 2016). Travelers want authentic, local experiences and more space. They want to pay for the things that matter most (HotelNewsNow, 2015).

Airbnb targets hosts and travellers. The company is looking for adventure-seakers, city-breakers, those who would like to travel and those ones who would like to earn "some" extra money by a business that allows them to do that by offering their apartments for short term rents (Le Jeune, 2016).

„While Airbnb has primarily served budget-minded tourists, it has been attracting a larger share of business travellers. This is due in part to cost - companies can save money on conferences, meetings and retreats. But the attractiveness of staying in someone else's home goes beyond the travel expense report." (Folger, 2016)

To measure the size of Airbnb business here you are some of the newest statistics and facts (Smith, 2017):

- Airbnb's total valuation $-\$ 30$ billion

- Number of Airbnb users - 100 million

- Number of Airbnb hosts - 640 thousand

- Number of Airbnb listings - 2.3 million

- Number of active countries - 191

- Number of active cities -65.000

- Top city for active Airbnb listings - Paris and London

"Airbnb's stated goal of $\$ 10$ billion in revenue by 2020 will likely come from a variety of categories - namely, vacation rentals, China and business travel," said Piper Jaffray analyst Michael Olson in a note to investors in March 2016 (Taylor, 2016). In spite of its impressive statistics, Airbnb experienced a series of ups and downs (Airbnb, 2016).
\end{abstract}


"Similar to other large cities in Europe, Airbnb has completely revolutionised the way many tourists arrange their stay in Budapest. Shortly after the hostel revolution of the early 2000s, the market of short-term rentals was further boosted by 8,100 apartments to rent out through Airbnb. This has transformed downtown Budapest districts to very lively and vibrant tourist destinations, especially during the peak summer season. The apartments available through the sharing economy platform bite into the business of hotels in Budapest. It is mostly mid-priced outlets which feel the competitive threat from the poorly regulated market and operators who often fail to pay taxes and other levies, putting hotels in a disadvantageous situation." (Euromonitor, 2016)

The web page called "AirDNA" deals with Airbnb data analysis. One can get an easy access to Airbnb host and property information, listing the number of bedrooms in the city, Airbnb rental activities, occupancy or even the most popular listings in a certain city regarding customer satisfaction. The number of properties started to increase from 2009 and in October 2016 the number of active rentals in Budapest was 8,351.

We can also see some basic information about rentals, guest reviews, the quality of Airbnb services and a pie chart that shows us the popularity of the different types of accommodations within Airbnb in Budapest.

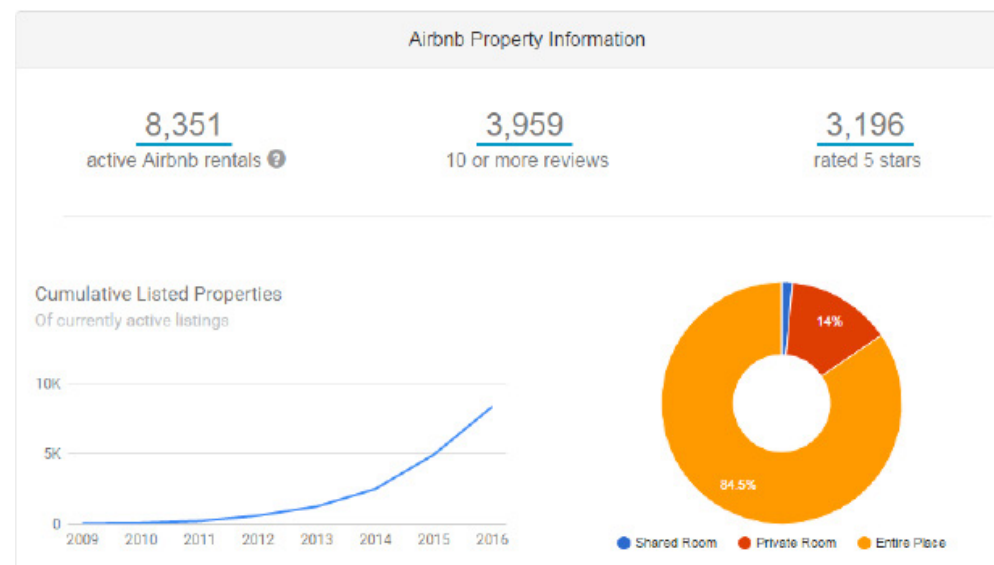

Figure 1. Airbnb Property Information

Source: https://www.airdna.co/city/hu/budapest, 14/10/2016/

Booking an entire house or apartment has always been more popular than sharing a room with an unknown person. This is exactly why entire places occupy $84.5 \%$ of total Airbnb flats in Budapest. The rate of private rooms is only $1.4 \%$ from the total, while shared rooms are the least favourite types of accommodation in the capital city of Hungary.

The seasonality is observable in the case of Airbnb occupancy, June-July-August are the most popular months.

Another significant component of AirDNA is the Airbnb rental activity that shows the months available for rent and the actual rents. 


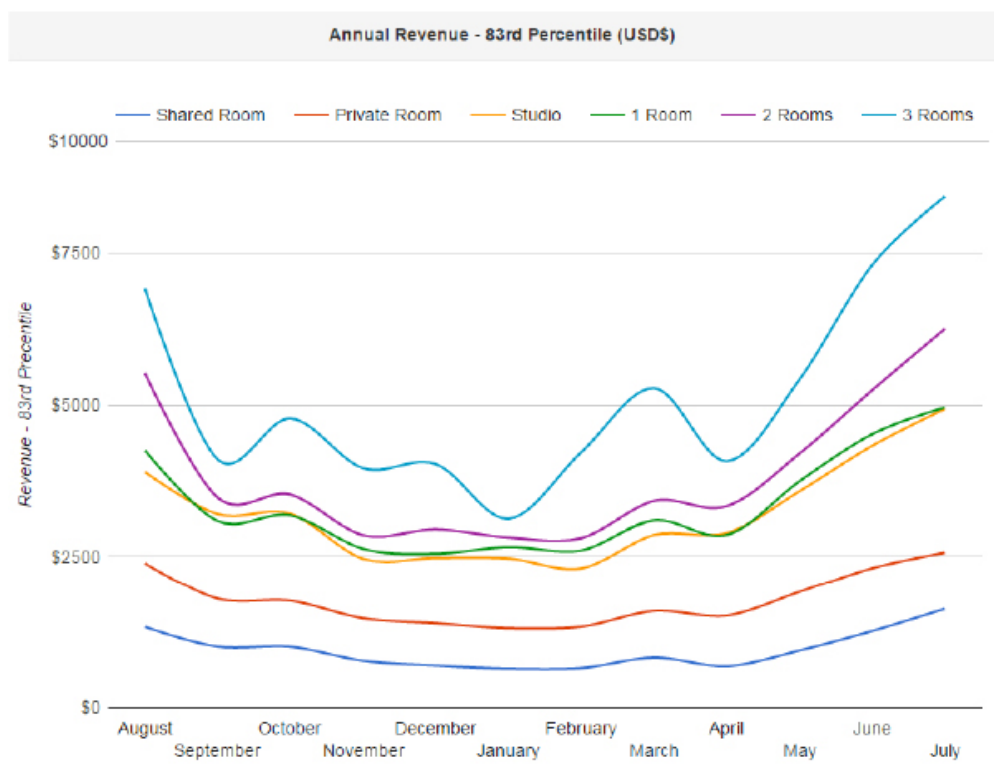

Figure 2. Annual Revenue

Source: https://www.airdna.co/city/hu/budapest, 14/10/2016/

Airbnb Rental Activity
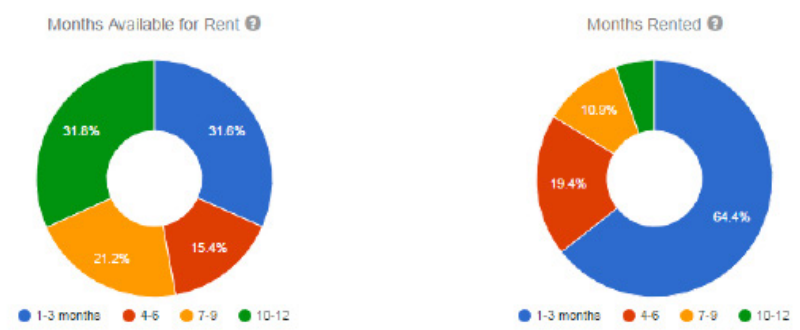

Figure 3. Airbnb Rental Activity

Source: https://www.airdna.co/city/hu/budapest, 14/10/2016/

In this case the two extremes are conspicuous: most of the months (from ten to twelve months) are available for rent. However, people tend to rent Airbnb places more frequently for one to three months.

As we could see active Airbnb rentals were 8351 in October of which nearly 3500 was in Budapest at that time. According to Hungarian Airbnb experts 70-90\% of the owners of these properties offered for rent do not registered the accommodation, so this information is not available on the Hungarian Central Statistical Office (KSH). 


\section{METHODOLOGY}

With the emergence of Airbnb new opportunities opened the eyes of a lot of tourists and made several places even more accessible. While it is very popular to write about the advantages, disadvantages, positive and negative effects of Airbnb, there is no data available anywhere about the characteristics of those people who choose Airbnb as a form of accommodation. One can only estimate the approximate number of them. This is the reason why it is worth to make a research about. Besides the demographics also the expenses and satisfaction will be investigated. We try to prove the credibility of this hypothesis (Bunyevácz, 2016):

"Most of the Airbnb guests tend to spend less on accommodation and more on additional services."

Two types of primary researches were used: a survey directed at Airbnb guests staying in Budapest and interviews with Airbnb hosts to gain both quantitative and qualitative data. In order to gain reliable data, we had to observe the situation from the two different aspects: from hosts' and guests' points of view.

Four interviews were conducted in October 2016 with four ladies, operating one to thirty apartments offered by Airbnb website. All the participants received the same 11 questions. We wanted to gain knowledge about everything hosts know about guests considering different aspects: nationality, age, gender, degree, financial background, clothing, interests, etc.

On the other hand, 104 questionnaires were filled out between July and November (2016) in order to gain a realistic thought about the characteristics of Airbnb guests. The questionnaires were filled out manually. Questions were analysed in the same way. At the time of the check-in participants were told to help us make a research about their characteristics, behaviour and spending and almost all of them proved to be helpful.

Multiple choice, short answer and scaling related questions were asked from participants. The 43 questions might seem a bit too much, but we needed all of them in order to get a clear picture of the subject of the research.

\section{Limitations}

In the case of secondary researches, the most serious barrier was the lack of academic literature available on the topic. Airbnb's tendencies are changing very fast (day by day) and it can be difficult to quote from different authors' articles as they might not be actual anymore. From participants' point of view two main limits must be mentioned. One of them is the confidential data that interviewees shared with us. On the other hand, it would have been important to reach more Airbnb clients to write a more precise conclusion at the end of the research. We have to take all these limitations into consideration upon analysing the results. 


\section{RESEARCH RESULTS}

The main findings provided by Airbnb hosts are the following:

The hosts receiving guests from different continents, but mainly from Europe (England, Russia, France, Italy) and North-America. The ratio of Hungarians is very low (5-10\%). The proportion of genders has been $50-50 \%$ or a little higher ratio in favour of male. The average age is approximately 30 , because most of the guests were young adults, few parents arrived with children or grandparents arrived with grandchildren. The most frequent guests are couples and small groups (friends). The clientele is well educated, well-dressed and belongs to the middle class with good financial background. The younger generation is more thankful at the time of the check-out. The older the people get, the more critic they become.

The Spanish nation turned to be the most enthusiastic and happy among all of clients while the ones from Asia are very polite (there were people who used the washing machine in order to leave clean sheets and bedclothes after themselves). Each guest is grateful for personal contacts and authentic information.

Their main purpose of their visit is city break: sightseeing, relaxation, visiting thermal baths and participating on activities Budapest offers for them, but approximately $10-15 \%$ of the customers came for conferences or other business purposes.

\section{Demographics}

After analysing the questionnaires, the following results came up. Most of the people (48) are between the age of 26 and 32. Only two participants were under the age of 18 (Figure 4). The rate of genders is the following: $63 \%$ of the participants are male, while $37 \%$ of the participants are female.

Only two of the participants had less than a high school degree, which can be explained as two of the participants are under the age of 18 . Almost $57 \%$ of the participants had bachelor degree, while nineteen clients had a graduate or master degree.

The number of nationalities participating in the survey was 20 (Figure 5). Among them we can distinguish 26 English (which is $25 \%$ of the total number of participants) and 15 American (from the USA).

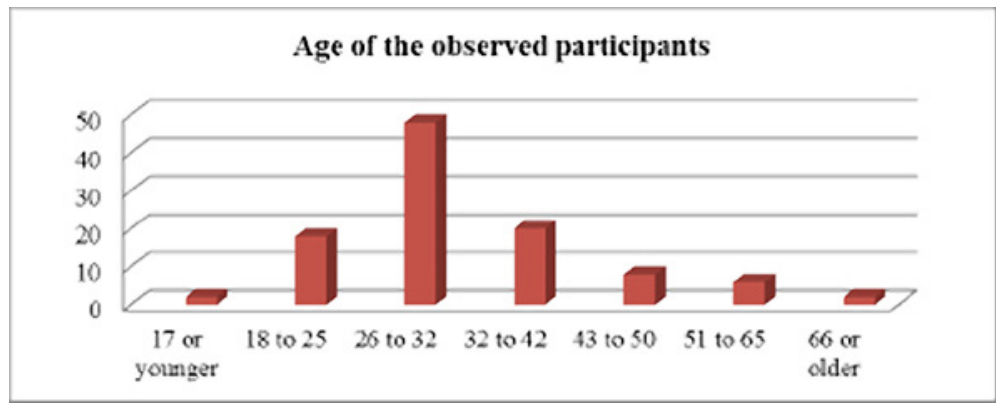

Figure 4. Age of the observed participants

Source: Own research 


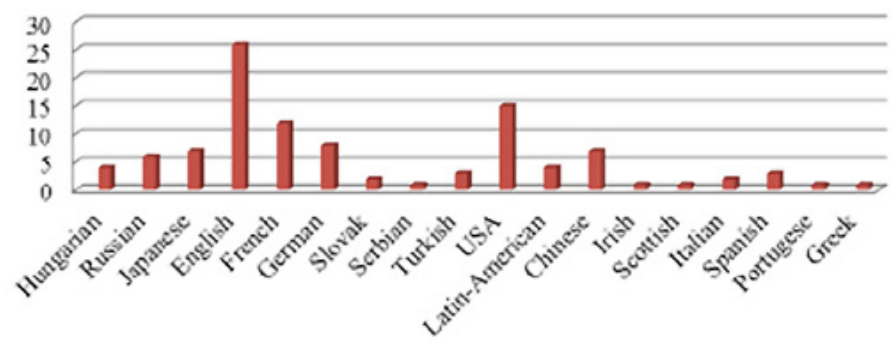

Figure 5. Nationality of the observed participants Source: Own research

Among the participants we could differentiate three unemployed, eight retired, sixteen students and seventy-seven employed people. $61 \%$ of the clientele are working full time, while $12.5 \%$ of them have only part-time jobs.

According to the monthly personal income of Airbnb clients who filled out the questionnaire (Figure 6), 27\% of the participants earn 1201 to 2000 Euros, while 22\% earns between 400 and 800 Euros per month. 16\% of the people earn less than 400 Euro in a month. One participant earns more than 3000 Euro per month.

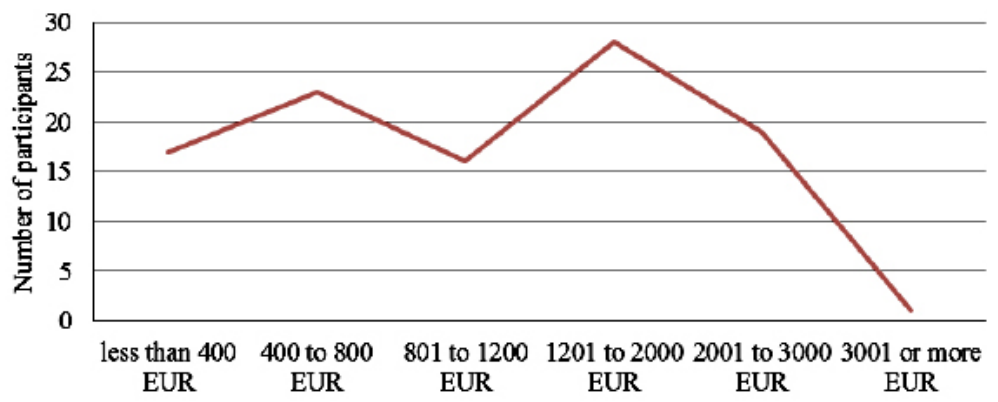

Figure 6. Monthly personal income

Source: Own research

The majority of the customers live with their partner and children currently (61\%) while $32 \%$ of the clientele live by their own and only $2.8 \%$ live with their parents.

$53.8 \%$ of the participants come from big cities, $31.7 \%$ from capital cities, $11.5 \%$ from small towns and only 3 people responded with the answer that tells us that they are from villages.

\section{Travel habits}

The second chapter of the questionnaire was the described travel habits. Out of 104 participants 67 travels once a year, 14 participants "less than 3-4 times a year”, 12 of them commented "rarely", 9 of them with an answer of „,3-4 times a year” and only 2 people stated that they travel monthly. 
The most common habit is to travel with family members (53), 11 of them most likely travel with friends and other 11 people stated that they travel with colleagues, while only 9 customers travel alone.

$82 \%$ of the participants arrived to Budapest by airplane (mostly budget airlines), $12 \%$ by car, $5 \%$ by train. Mostly city breakers filled out the questionnaire (65\%). They also marked the option of partying in the city. Four people came to visit friends and/or relatives. Eleven people arrived with business purpose (10.5\%), 8 people for healing, 46 people with cultural purposes and 2 people to do sport here.

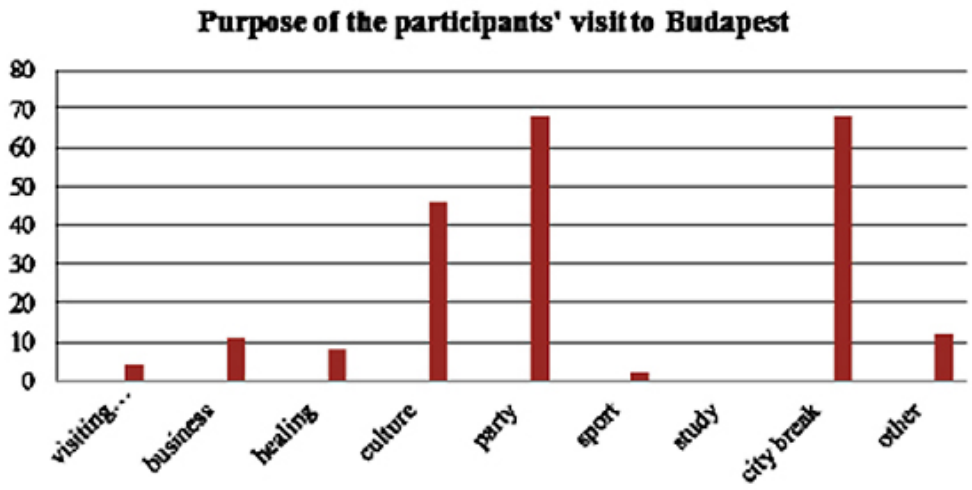

Figure 7. Purpose of travel Source: Own research

There was an „other” option here as well. „To have fun” and „To get to know a different culture" and „Bachelor party” were the three additional reasons of visiting Budapest.

\section{Accommodations choice}

In case of the most important factor that influences their choice on accommodation price was marked 42 times, location was the number one influencing factor for 38 people and quality was indispensable for 25 participants.

All the participants had to mark a number on a scale from 0 to 5 about the reasons of choosing Airbnb in the next section of the questionnaire. The different options and their belonging average values will appear in Figure 8.

According to Figure 8 the most popular reasons of choosing Airbnb are the cheap prices of the apartments and all the feedbacks that the system provides.

In the next part (Figure 9) Budapest as a destination is going to be rated in the same way (on a scale from 0 to 5) according to the opinion of the observed Airbnb clientele. The reasons of choosing Budapest are the followings: 


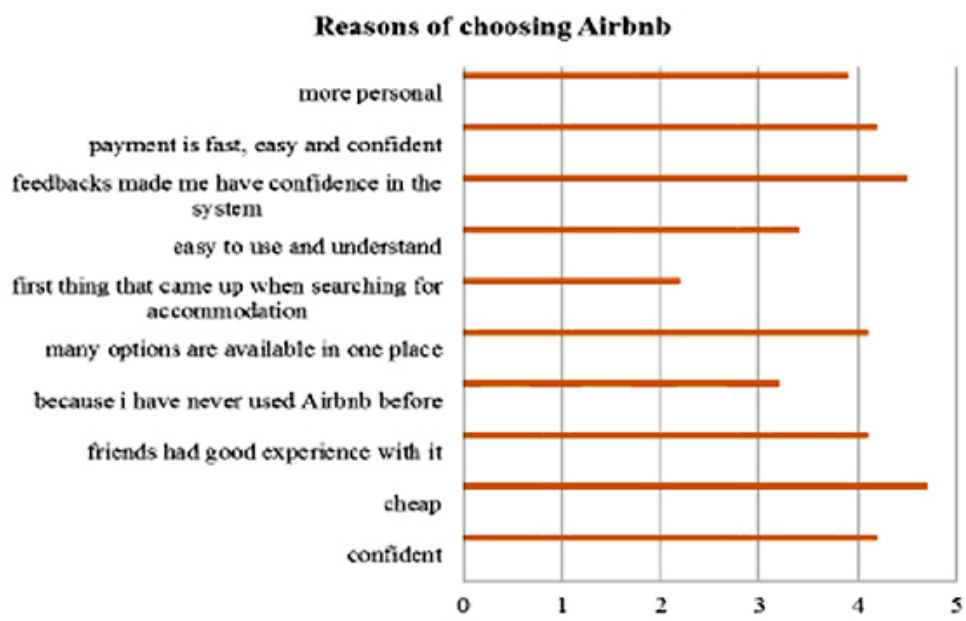

Figure 8. Factors influencing the respondent choice of accommodation Source: Own research

Figure 9. Why to come to Budapest?

\begin{tabular}{|l|c|}
\hline Reason of choosing Budapest & Average value (from 1-5) \\
\hline I am interested in the city & 5 \\
\hline Budapest has a good image & 4,2 \\
\hline Budapest is a cheap city compared to other European cities: & 3,1 \\
\hline Budapest is near and easy to reach & 3,8 \\
\hline Others recommended the city & 3,2 \\
\hline The flight was cheap & 2,9 \\
\hline I heard from Budapest in the news/read some advertisements & \\
\hline
\end{tabular}

Source: Own research

The next question was: „From where did you hear about Airbnb?” Internet was the most common answer on this question. $80 \%$ of the clientele chose this option, while the other $20 \%$ claimed that they heard about the city from friends and/or relatives.

The majority of the observed customers (Figure 10) stayed from 1 to 4 days in the city.

The observed 104 guests spent altogether 293 nights in Budapest. Taking all this data into consideration the average length of stay of the observed Airbnb guests in Budapest was 2.81 days. 
Lenght of stay of observed Airbnb guests

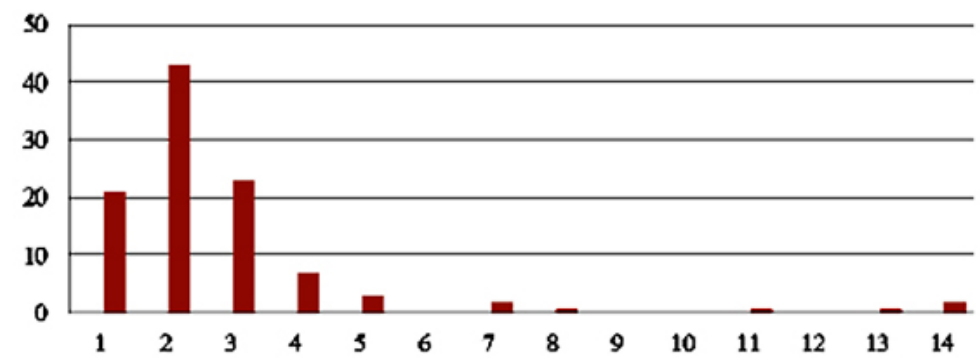

Figure 10. Lenght of stay of the participants

Source: Own research

\section{Expenditures}

The first question of the section was: „How many Euros had you planned to spend before your arrival to Budapest?" Counting an average number from the received answers participants expected to spend an average 362 Euros during their stay. This number in reality was averagely 372 Euros.

Observing the types of services used we can say that thermal baths, sightseeing services, day-time and night-time activities, catering units can benefit from Airbnb as well, which means that Airbnb has a huge impact on these types of services and service providers.

The following table indicates the different services used by Airbnb guests including their expectations and the indication of those services that these clients actually used (Figure 11) during their stay in Budapest.

Figure 11. Comparison of guests' expected and consumed services used in Budapest

\begin{tabular}{|l|c|c|}
\hline Services: & Expectation & Reality \\
\hline Accommodation & 104 & 104 \\
\hline Hospitality (Restaurants, bars, etc.) & 104 & 104 \\
\hline Transportation & 96 & 98 \\
\hline Entertainment & 94 & 94 \\
\hline Nightlife (pubs, clubs, bars, etc.) & 88 & 90 \\
\hline Sport & 4 & 6 \\
\hline Sightseeing services & 62 & 68 \\
\hline Thermal baths & 56 & 58 \\
\hline Other & 4 & 27 \\
\hline
\end{tabular}

Source: Own research

Some additional services were mentioned in this section: shooting, beer bike, massage, go karting and boat cruises. 
Question 38 related to the means of transportation (bus, tram, train, boat, taxi, trolley bus, bicycle, beer bike, rickshaw, funicular and metro were the options). Buses and taxis were the most popular ones. Almost $50 \%$ of the guests used them. Tram, boats, beer bike and rickshaw were not really expected to be used during the stay of the clientele in Budapest, but they were used quite frequently. There was a comment from a guest saying that Budapest has very good transportation services.

\section{Satisfaction}

In the last part of the questionnaire we were interested in the satisfaction of the participants considering both negative and positive experiences in case of Airbnb and Budapest. The most positive experiences were the followings mentioned in comment boxes: comfortable location, attentive host, nice buildings, good location, beautiful and modern city. There were only three negative experiences (running out of toilet paper, spider on the wall and the cleanliness of the apartment).

There were two scaling questions asking about the satisfaction of the guests with Airbnb and Budapest on a scale from 0 to 10 (Figure 12).

Figure 12. Satisfaction of Airbnb guests with Airbnb and Budapest

\begin{tabular}{|c|c|c|}
\hline Scale: & $\begin{array}{c}\text { Satisfaction with Airbnb: } \\
\text { (number of people marking } \\
\text { this option) }\end{array}$ & $\begin{array}{c}\text { Satisfaction with Budapest: } \\
\text { (number of people marking } \\
\text { this option) }\end{array}$ \\
\hline 1 & 0 & 0 \\
\hline 2 & 0 & 0 \\
\hline 3 & 0 & 0 \\
\hline 4 & 0 & 0 \\
\hline 5 & 1 & 8 \\
\hline 6 & 2 & 3 \\
\hline 7 & 6 & 7 \\
\hline 8 & 12 & 22 \\
\hline 9 & 9 & 12 \\
\hline 10 & 74 & 52 \\
\hline
\end{tabular}

Source: Own research

From here we can clearly see that 5 was the worst rate and most of the people (71\%) said that they were $100 \%$ satisfied with Airbnb and their overall experience in Budapest (50\%) as well.

One participant said that he/she will never return to Budapest. 12\% of the participants marked 5, while six people pointed 6 , twelve guests said 7 , fourteen people marked 8 , twenty-one people ticked 9 and finally, $36.5 \%$ of the participants said that they will $100 \%$ return to Budapest, which is a very good rate again and an excellent feedback for the city. 


\section{CONCLUSION}

Concerning the Airbnb facts, we can conclude how huge this new phenomenon of sharing economy has become in the past couple of years. The same tendency is observable also in Budapest (Hungary).

Its Airbnb clientele stays only 2.8 days, they spend 134 Euros/day. It means that even if most Airbnb guest chooses Airbnb because of its low prices, they still spend averagely more money on services. So, the original hypothesis has been confirmed.

Although location is very important for all the guests when they choose an accommodation, price is still the most influencing factor in case of Airbnb. The average age of guests among the lower price category apartments is approximately 30 ; while this number is higher in case of those people who choose higher category apartments. Approximately $10-15 \%$ of the Airbnb clientele comes to Budapest with business purposes, which means that it is quite frequent among employers to book accommodation through Airbnb. The reason of it might be the discount Airbnb offers for corporate travellers, which is 50 Euros, a very considerable amount. We can also conclude that most of the Airbnb guests are city breakers (64\%) using a wide range of services. However, we also got to know that these tourists had not expected to use most of the services before their arrival. Budapest is rated as a very satisfactory city worth to visit. Most of the observed clients plan to return in the future, because they enjoyed the wide range of services Budapest offers for its visitors.

\section{REFERENCES}

AIRBNB (2016). Code of Ethics. Available at: http://airbnb-marketing.blogspot. rs/2012/09/ch-3-ethics-and-social-responsibility.html (Accessed: 11/01/2017)

AirDNA (2016): Budapest, Hungary Airbnb Data and Analytics. Available at: https:// www.airdna.co/city/hu/budapest (Accessed: 11/12/2016)

BUNYEVÁCZ, A. (2016): Situation analysis of Airbnb demand in Budapest in 2016. BBS, Budapest

EDELMAN, B. G. and GERADIN, D. (2015): Efficiencies and Regulatory Shortcuts: How Should We Regulate Companies like Airbnb and Uber?. Stanford Technology Law Review, Forthcoming, 16-026. Available at: https://papers.ssrn.com/sol3/papers. cfm?abstract_id=2658603\#\# (Accessed: 18/06/2017)

EUROMONITOR (2016): Travel in Hungary-Country report. Available at: http://www. euromonitor.com/travel-in-hungary/report (Accessed: 15/03/2017)

FOLGER, J. (2016): The Pros and Cons of Using Airbnb. Available at: http://www.investopedia.com/articles/personal-finance/032814/pros-and-cons-using-airbnb. asp?performancelayout=true (Accessed: 22/01/2017)

GUTTENTAG, D. (2015). Airbnb: disruptive innovation and the rise of an informal tourism accommodation sector. Current Issues in Tourism, 18 (12), 1192-1217.

HOTEL NEWS NOW (2015): The impact of the sharing economy on hotels - An analysis of Airbnb and alternative accommodations. Available at: 
http://www.hotelnewsnow.com/media/File/PDFs/Reports/HNN_SharingEconomy_ compressed(1).pdf (Accessed: 11/02/2017)

HUNGARIAN CENTRAL STATISTICAL OFFICE (2016): Tourism and catering data. Available at: https://www.ksh.hu/stadat_eves_4_5 (Accessed: 15/02/2017)

LE JEUNE, S. (2016): The Sharing Economy (2016. July), Schroders. Available at:

http://www.schroders.com/en/SysGlobalAssets/digital/resources/pdfs/2016-08-thesharing-economy.pdf (Accessed: 15/03/2017)

LIEBER, R. (2012). A Warning for Hosts of Airbnb Travellers. The New York Times, Available at: http://www.nytimes.com/2012/12/01/your-money/a-warning-forairbnb-hosts-who-may-be-breaking-the-law.html (Accessed: 07/05/2017)

OSKAM, J. and BOSWIJK, B. (2016): Airbnb: the future of networked hospitality businesses. Journal of Tourism Futures, 2(1), $22-42$.

PWC (2015): Consumer intelligence series -The Sharing Economy. pp. 9-10. Available at: https://www.pwc.com/us/en/technology/publications/assets/pwc-consumer-intelligence-series-the-sharing-economy.pdf (Accessed: 01/03/2017)

SMITH, C. (2017): 90 Amazing Airbnb Statistics and Facts,

http://expandedramblings.com/index.php/airbnb-statistics/ (Accessed: 07/03/2017)

TAYLOR, H. (2016): How Airbnb is growing a far-flung global empire. CNBC. Available at: http://www.cnbc.com/2016/06/01/how-airbnb-is-growing-a-far-flung-globalempire.html 